\title{
What are key components when creating an innovative Crowdsourcing business model?
}

\author{
Yanfeng Liu*, Yanmeng Xu*, Shengfeng Qin+ \\ *College of Engineering, Design and Physical Sciences, Brunel University London, UB8 3PH, UK \\ +School of Design, Northumbria University, Newcastle upon Tyne, NE1 8ST, UK \\ *Corresponding author: Yanfeng Liu (e-mail: yanfeng.liu@brunel.ac.uk) \\ Yanmeng Xu (email: yanmeng.xu@brunel.ac.uk)
}

\begin{abstract}
Crowdsourcing, as a new business model, can effectively reduce the cost of enterprises, stimulate public participation's passion and enable enterprises to obtain multi-channel innovation. From the point of view of business model, Crowdsourcing can effectively improve the enterprise's overall value proposition, value creation, value transfer and value network construction. Although nowadays Crowdsourcing is widely applied across industries, it is still imperfect in implementing at a practical level, especially when adapt it to fit for different industries. This paper focuses on (1) the identification of key components in an innovative business model, and (2) discussion on how to create an innovative Crowdsourcing business model, which forms a framework for developing Crowdsourcing business models at different levels of detail such as types of industries, types of platforms and types of tasks.
\end{abstract}

Keywords- Crowdsourcing, business model, value creation, value capture, value proposition, value creation, value transfer, value network

\section{THE ORIGIN OF CROWDSOURCING AND ITS BUSINESS MODEL}

Based on the advent of Web2.0 era, the Internet has greatly changed the way of life and living style of the public, especially when human beings entered the new century, "digital generation" has gradually become the main productive forces. Their enthusiasm for participating community governance is unprecedented high, and nonstop generously contribute their knowledge and share their experiences. At the same time, due to the descending of close-innovation model for value creation, the enterprise had to seek help from outside to seek more unique ideas and efficient products. The internal operation of the enterprisebased close-innovation model is becoming less costeffective and high risk in $R \& D$ failure, which makes "Crowdsourcing" emerged in this Internet era and widely spread.

"Crowdsourcing" is first brought by Jeff Howe in June 2006. Jeff (2006) believes that "Crowdsourcing" is a game changing method for business in which enterprises subcontract work to the public through the Internet, any participant can use the web platform to deliver ideas, solve problems, and earn commissions [1,2]. The key premise of its implementation is the network platform to attract potential participants. Daren defines Crowdsourcing as an online, distributed problem-solving and production model, and another widely cited definition for "Crowdsourcing" is: the participants through Internet to share their own wisdom, knowledge, ability, experience into practical benefits. No matter from which perspective to analyse Crowdsourcing business model, it would summarize that Crowdsourcing has the following three characters: One is completely based on Internet and connecting outsource people. The second is to break through corporate boundaries and limits, both in operational limits and financial limits, to maximize the usage of external resources. Third, the object is uncertain and the outcome would be flourishing. The basic model of Crowdsourcing consists of a contracting seeker, a contracting solver, and an intermediary platform. Seeker will release the task in the intermediary platform to seek potential public solvers, and the successful solver would obtain the reward from seeker after completing the task. Compared with the traditional business model in operation, Crowdsourcing business model demonstrates few distinguished features. The first one is that successful solver received a much lower rewards than the market price thus the motivation for them to participate is not merely financial rewards; the second is seeker has not cast a clear objectives to be achieved, which means a not well defined and blurred objective could stimulate unexpected flourishing outcome in some way; the third one is, the value created by Crowdsourcing is far more than single target value in a meanwhile it could cultivate a series of value chain during the process of solvers participating.

\section{PRINCIPLES AND COMPONENTS OF CROWDSOURCING BUSINESS MODEL}

Teece (2010) defines a business model articulates the logic and provides data and other evidence that demonstrates how a business creates and delivers value to 
customers. It also outlines the architecture of revenues, costs, and profits associated with the business enterprise delivering that value [3].

When designing a suitable Crowdsourcing business model, all elements above are firmly interrelated and the core challenge is to build a sustainable competitive advantage at the new era. In short, a good business model let the enterprise creates and delivers value to customers, and then converts achievements received to profits. Since enterprises across all industries are embracing internetbased digitization strategies to expand or improve their business, a well-designed Crowdsourcing business model should balance the provision of value to customers with the capture of value by the provider. Value creation and value capture, those two major principles [4] of a business model are the key elements when to design, implement, and refine a Crowdsourcing business model for enterprise.

By studying some scholar' s previous researches for corporate strategy innovation, including Chesbrough and Rosenbloom (2002)[5], Schön (2012)[6], Osterwalder and Pigneur (2010)[7], a list of business model components could be extracted as following:

1) Value Proposition: Customer needs, Products and services

2) Revenue Model: Pricing Logic, Customer interaction, Channels, Value creation

3) Cost model: Core capabilities and activities, Value network, Value transfer

Those three components consist an ecosystem for enterprise business model creation and interact internally as the following figure 1, which provide us as a guideline when think about transforming business model into Crowdsourcing.

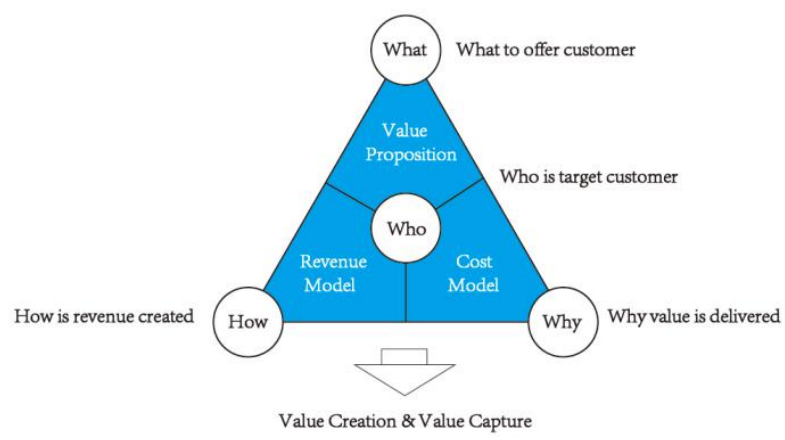

Figure 1: Three components of Business model

\section{CREATE CROWDSOURCING BUSINESS MODEL ON COMPETITIVE ADVANTAGE FRAMEWORK}

Crowdsourcing business model is a kind of innovation to the traditional business model, and successful business model is embodied in improving the core competitive advantage of enterprises. After identifying the composition of the business model, we can examine the Crowdsourcing mechanism in perspective of competitive advantage framework. According to the research of Chesbrough (1996)[8] and other scholars [9,10,11], we study the mechanism of value proposition, value creation, value transfer and value network as the four essential components for enterprise competitive advantage, help to generate ideas of how to create a successful Crowdsourcing business model.

\section{(1) Value proposition}

Value proposition is what enterprise claims its products and services can bring unique value for consumers, and in reflect customers can perceive the sum of a series of vested interests[12]. Enterprises to create Crowdsourcing business model firstly have to determine their own value proposition, which need to take into account integrally customer value, public value and the value of stakeholders. Different from the traditional business model, to create the value of Crowdsourcing relies on each fragments among the network, including all visible participants and invisible stakeholders. By stimulating the intrinsic motive of public participation in Crowdsourcing, enterprise transforms those motivations into the public value creation, in order to attract public to participate in the Crowdsourcing to realize such value for the enterprise. For an innovative Crowdsourcing business model, the value proposition will force the enterprise to focus entirely on their true value creation for their own customers. When Enterprises in the way of proposing value proposition, they have to fully estimate their own strategic resources and core competencies, as a basis to find a new combination of elements and applications to achieve value innovation.

\section{(2) Value creation}

Value creation refers to a series of business activities and their cost structure in which enterprises produce and supply products or services that meet the needs of target customers[13]. In the traditional business model, the main value creator is the enterprise itself, and Crowdsourcing business model using open product R\&D process from external resources; anyone can rely on open source production in the form of Crowdsourcing. To create a Crowdsourcing business model, the enterprise should pay attention to the following three aspects: First, carefully design a reward ecosystem including a smart price policy, 
a clear defined voting system, a well-maintained discussion and feedback mechanism, and an honor reward system rather than only financial rewards. Second, increase the communication frequency between the two sides, reducing the communication cost for the seeker and solver in the search, negotiation, implementation and other aspects[14]. By the adequate of human resources, the enterprises can do value creation by massive solution. Thanks to each individual is good at different fields, this cross-professional innovation often contains great potential, then unexpected value created, and produce more in line with consumer demand for products and services. Third, Crowdsourcing business model embodies a culture of public participation, that is, through the participation of the majority of amateurs, so that they create a more in line with their own needs across the barriers of individual circumstance. Pay special attention for public participation in product or service design, production, sales and other sectors would efficient promote the success to personalized products or services.

\section{(3) Value transfer}

The nature of the value transfer means the enterprise ' s profits through customer value-added services then deliver to the customer. In the crowd, the value flows in both ways. The enterprises provide better products or services to customers and customers also provide enterprises with their knowledge and ideas [15]. In this process, enterprise and customer in accordance with their value proposition to achieve their own value. In order to create a successful Crowdsourcing business model, the value of the Crowdsourcing business model relies heavily on the Crowdsourcing platform, which provides a communication platform for both sides. Crowdsourcing platform, there are two forms, one is self-built platform, the second is a third-party platform[16]. When face the choice of value transfer channels, enterprises should combine with their own ability to integrate resources and control the process then determine which way is more suitable. In general, for a large enterprise, who are able to build a complete Internet application technology, is suitable for self-built platform for more flexible in procedure control and intellectual property protection, but subject to big/good enough engagements of the crowd. For enterprises who are not good at technology or lack of resources in building their own network system, the third-party provider for Crowdsourcing campaign is more easy and simple, enterprises can significantly save time and resources in seeking right crowd group by third-party Crowdsourcing platform.

\section{(4) Value network}

Value network is the relationship of value generation, distribution, deliver and use formed by mutual influence among stakeholders[17]. Crowdsourcing is developed with the popularity of Internet use, it not only blurs the boundaries between employees and customers, but also greatly extends the boundaries of business organizations, so that enterprises transformed from the value chain capture to the value network capture[18]. The value network breaks the linear model of traditional value chain and the sequence of value activities, and reconstructs the original value chain around the segments of the value network[19]. When create a well-designed Crowdsourcing business model, it is essential to take all aspects of the value chain and the different subjects in accordance with the overall value into account, in order to achieve the optimal principle of mutual convergence, integration and dynamic interaction, to promote Crowdsourcing in an orderly manner. Enterprises should pay more attention to the value realization and connection of other essentials on the value network rather than paying attention to the realization of their own value[20], so that to improve the Crowdsourcing interaction between the main value behaviors, thus in consequence, to enhance the level of value creation.

\section{A FRAMEWORK FOR CREATING A CROWDSOURCING BUSINESS MODEL}

Based on the discussion above, we create a framework model for creating a Crowdsourcing business model, consisting of four pillars and their key building bricks as figure 2 .

This framework could be utilized as an initial tool before launching any Crowdsourcing campaign then to establish a sustainable Crowdsourcing business model, or could be adapted as an examine tool to modify/adjust any ongoing Crowdsourcing activities to achieve better innovative performances/outcomes. Enterprises can scrutinize themselves at the initial stage according to the characters of tasks, resources, or themselves, then break down the result into bricks according to the category of four pillars. Pillars as the four aspects of competitive advantage for enterprise reflects the overall perspective values, which could involve the most internal and external participants' interest and needs. 


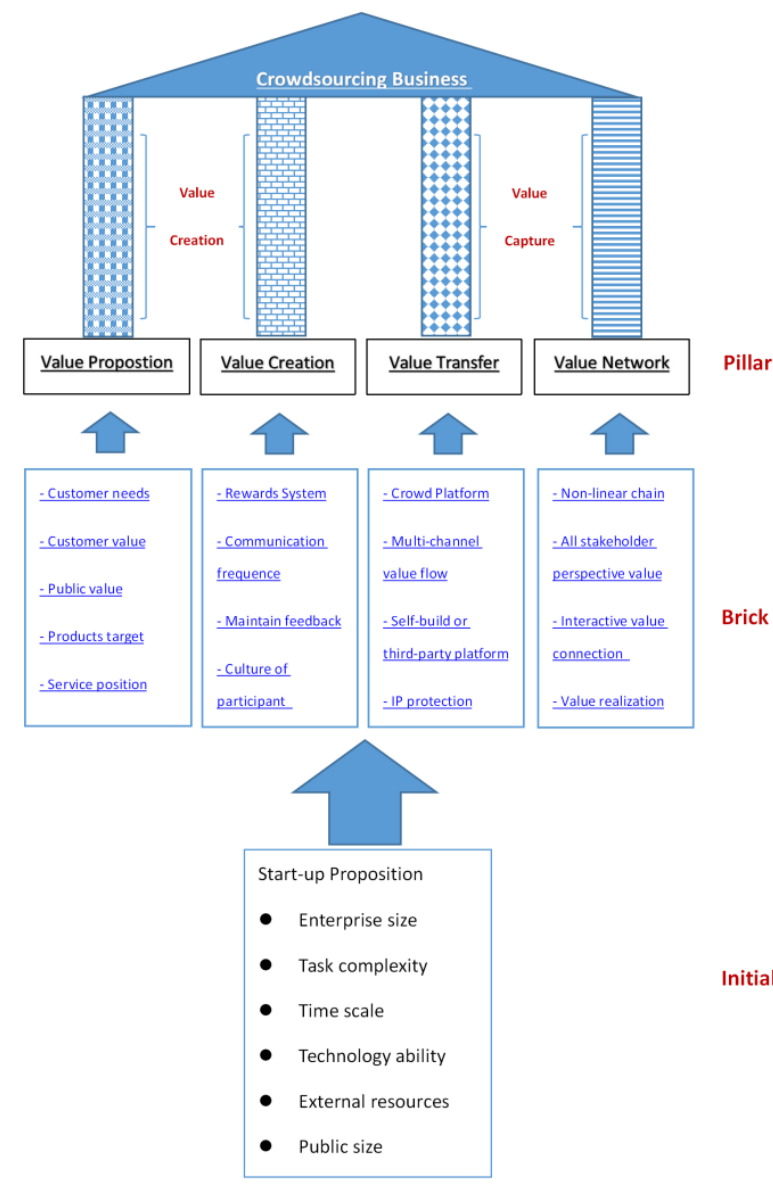

Figure 2: framework for creating Crowdsourcing Business model

\section{CONCLUSION}

Crowdsourcing as an emerging business model is increasingly popular [21]. As an internet-based innovative type of business model, it is necessarily to understand the benefits, opportunities and limitations of this innovation mechanism, and to make well-informed innovation policy decisions on support mechanisms for feasible, sustainable, productive and cost-efficient Crowdsourcing. From the point of view of business model component, to build a successful Crowdsourcing business model is about how to effectively improve the performance and mechanism of value proposition, value creation, value transfer and value network construction, thus to enhance the competitive advantage for the enterprise.

And we have to be aware that, developing a successful Crowdsourcing business model is insufficient to assure competitive advantages in Crowd innovation performance. But Crowdsourcing business model innovation itself could be an innovative pathway to adapt sufficiently differentiated behaviors for future business challenges. This paper has generally identified the framework for how to create an innovative Crowdsourcing business model, and it remains further discussion for developing a mechanism to build more specified Crowdsourcing business model in different task level.

\section{REFERENCES}

[1] Howe, Jeff, "The rise of crowdsourcing," Wired magazine, vol. 14, 2006, pp. 1-4.

[2] Howe, J. (2006a) 'Crowdsourcing: A Definition', Crowdsourcing: Tracking the Rise of the Amateur (weblog, 2 June)

[3] David J. Teece (2010), "Business Models, Business Strategy and Innovation “, Long Range Planning, vol 43

[4] Chesbrough, H., Vanhaverbeke, W., West, J. (2006), Open Innovation: Researching a New Paradigm, Oxford University Press

[5] Chesbrough H, Rosenbloom RS (2002) "The role of the business model in capturing value from innovation: evidence from Xerox Corporation's technology”. Ind Corp Chang 11(3):529-555

[6] Schön O (2012) "Business model modularity-a way to gain strategic flexibility?”, Consult Manag 56(2):73-78

[7] Osterwalder A, Pigneur Y (2010) "Business model generation: a handbook for visionaries, game changers, and challengers.” Wiley, Hoboken, NJ

[8] Chesbrough HW, Teece DJ (1996) “Organizing for innovation: when is virtual virtuous?" Harv Bus Rev 74(1):65-73

[9] D’Aveni R, Dagnino BG, Smith KG (2010) “The age of temporary advantage”. Strateg Manag J 31(13):1371-1385

[10] Porter ME (1980) "Competitive strategy: techniques for analyzing industries and competitors". Free Press, New York

[11] Teece DJ (1988) "Capturing value from technological innovation: integration, strategic partnering, and licensing decisions”. Interfaces 18(3):46-61

[12] Teece DJ (2010) "Business models, business strategy and innovation”. Long Range Plan 43(2):172-194

[13] El Sawy OA, Pereira F (2013) "Business modelling in the dynamic digital space: an ecosystem approach”. Springer, Berlin

[14] Ghosh S (1998) "Making business sense of the Internet". Harv Bus Rev 76(2):126-135

[15] Kelley, B. (2011) “A guide to open innovation and crowdsourcing”. In: Sloane, P. (ed.)

[16] Evans PC, Gawer A (2016) "The rise of the platform enterprise: a global survey”. Center for Global Enterprise, New York

[17] Birkinshaw J, Ansari S (2015) Understanding management models: going beyond "what" and "why" to "how" work gets done in organizations. In: Foss NJ, Saebi T (eds) Business model innovation: the organizational dimension. Oxford University Press, Oxford, pp 85-103

[18] Brousseau E, Penard T (2007) The economics of digital business models: a framework for analyzing the economics of platforms. Rev Netw Econ 6(2):81-114

[19] Carpenter H. Motivating the crowd to participate in your innovation initiative[J]. A guide to open innovation and crowdsourcing, 2011: 53-81.

[20] E Estellés-Arolas, F González-Ladrón-De-Guevara (2012), "Towards an integrated crowdsourcing definition", Journal of Information science 38 (2), 189-200

[21] Castella, T. de (2010) 'Should we trust the wisdom of the crowds?'BBC News 5 July 2010, $<$ http://news.bbc.co.uk/2/hi/uk_news/magazine/8788780.st m> latest accessed 14 May 2018 